\title{
P008. Alexithymia and chronic migraine with medication overuse: what relationship?
}

\author{
Sara Bottiroli ${ }^{*}$, Federica Galli ${ }^{2}$, Michele Viana ${ }^{1}$, Grazia Sances $^{1}$, Marta Allena ${ }^{1}$, Natascia Ghiotto ${ }^{1}$ Elena Guaschino ${ }^{1}$, \\ Giorgio Sandrini ${ }^{1,3,4}$, Cristina Tassorelli ${ }^{1,3,4}$, Giuseppe Nappi ${ }^{1,4}$ \\ From Abstracts from the 1st Joint ANIRCEF-SISC Congress \\ Rome, Italy. 29-31 October 2015
}

\section{Background}

Alexithymia is a personality trait characterized by the inability to identify and express emotions. Neuroimaging studies showed specific neural correlates in alexithymic subjects [1] and pathological scores of alexithymia in several chronic pain populations and in episodic migraine [2,3]. There is also evidence of a positive association between alexithymia, depression, and anxiety in migraine patients. So far, no study has evaluated alexithymia in medication-overuse headache patients $(\mathrm{MOH})$ (progressed by migraine) versus episodic migraine patients (MIG). The present study was aimed to evaluate whether $\mathrm{MOH}$ individuals differ from MIG as regards alexithymia scores and to investigate the association of alexithymia with headache characteristics.

\section{Materials and methods}

We recruited 99 patients suffering from $\mathrm{MOH}(\mathrm{n}=54$; $81.5 \%$ female; age: $41.6 \pm 10.9$ ) evolved from migraine (chronic migraine $+\mathrm{MOH})$ or MIG $(\mathrm{n}=45 ; 71.6 \%$ female; age: $41.0 \pm 9.3)$ at the Headache Centre of the "Mondino" Institute of Pavia. Diagnosis in the 2 groups was operationally defined according to the ICHD-III $\beta$ criteria. Patients were evaluated using the Toronto Alexithymia Scale (TAS-20), which uses a five-point Likert response scale and has a three-factor structure consisting of: (1) Difficulty in identifying feelings, (2) Difficulty in describing feeling, and (3) Externally oriented thinking. Demographic and clinical information were collected as well.

\section{Results}

According to multiple binary logistic regression analysis, MIG and $\mathrm{MOH}$ patients were comparable in terms of

\footnotetext{
* Correspondence: sara.bottiroli@mondino.it

'Headache Science Centre (HSC), C. Mondino National Neurological Institute, Pavia, Italy

Full list of author information is available at the end of the article
}

demographic characteristics, whereas they differed for some characteristics of illness (age of migraine onset, duration of illness, frequency of headache), disability and QoL, as well as for depression levels. $\mathrm{MOH}$ patients scored higher than MIG on two of the three alexithymia facets, which were those concerning difficulties in identifying $(\mathrm{MOH}=19.1 \pm 6.7$, MIG $=13.8 \pm 6.7, \mathrm{p}<0.001)$ and describing feelings $(\mathrm{MOH}=14.4 \pm 4.5, \mathrm{MIG}=11.6 \pm 4.8$, $\mathrm{p}=0.003)$. Groups were instead comparable in terms of externally oriented thinking $(\mathrm{MOH}=18.6 \pm 4.2, \mathrm{MIG}=$ $18.0 \pm 4.1, \mathrm{p}=0.50)$. Significant correlations resulted between alexithymia and illness characteristics (e.g., headache frequency, perceived disability, and QoL).

\section{Conclusions}

Our results show a specific alexithymic profile in our $\mathrm{MOH}$ population. These findings suggest that alexithymia could represent a risk factor in the transformation from episodic migraine into the chronic subtype with medication overuse. Early and appropriate interventions aimed at improving emotional awareness and expression could then represent a further preventive measure to avoid drug-induced headache.

Written informed consent to publish was obtained from the patient(s).

Conflicts of interests

None.

\section{Acknowledgements}

This research was supported by a Grant of the Ministry of Health to the Mondino Institute (Current Research 2013-2015).

\section{Authors' details \\ 'Headache Science Centre (HSC), C. Mondino National Neurological Institute, Pavia, Italy. ${ }^{2}$ Department of Health Sciences, University of Milan, Milan, Italy. ${ }^{3}$ Department of Brain and Behavioural Sciences, University of Pavia, Pavia, Italy. ${ }^{4}$ University Consortium for Adaptive Disorders and Head pain, Pavia, Italy.} zero/1.0/) applies to the data made available in this article, unless otherwise stated. 


\section{References}

1. Pouga L, Berthoz S, de Gelder B, Grezes J: Individual differences in socioaffective skills influence the neural bases of fear processing: the case of alexithymia. Hum Brain Mapp 2010, 31(10):1469-1481.

2. Shibata M, Ninomiya T, Jensen MP, Anno K, Yonemoto K, Makino S, et al: Alexithymia is associated with greater risk of chronic pain and negative affect and with lower life satisfaction in a general population: the Hisayama Study. PLos One 2014, 9(3):e90984.

3. de Andrade Vieira RV, Vieira DC, Gomes WB, Gauer G: Alexithymia and its impact on quality of life in a group of Brazilian women with migraine without aura. J Headache Pain 2013, 14:18.

doi:10.1186/1129-2377-16-S1-A150

Cite this article as: Bottiroli et al:: P008. Alexithymia and chronic migraine with medication overuse: what relationship? The Journal of Headache and Pain 2015 16(Suppl 1):A150.

\section{Submit your manuscript to a SpringerOpen ${ }^{\mathcal{O}}$ journal and benefit from:}

- Convenient online submission

- Rigorous peer review

- Immediate publication on acceptance

- Open access: articles freely available online

- High visibility within the field

- Retaining the copyright to your article

Submit your next manuscript at $\gg$ springeropen.com 